\title{
In-vivo and in-vitro steroidogenic activity of post- ovulatory ovarian follicles of the rabbit
}

\author{
K. G. Osteen* and T. M. Mills \\ Department of Endocrinology, Medical College of Georgia, Augusta, Georgia 30912, U.S.A.
}

\begin{abstract}
Summary. Pseudopregnancy was induced in rabbits by injection of $50 \mathrm{i} . \mathrm{u}$. hCG into the lateral ear vein. Blood was collected on Days 0, 1, 2 and 6 after hCG from the lateral ear vein and, in some studies, from the ovarian vein as well. Ovaries were collected on Days $0,1,2$ or 6 after hCG injection, and follicles ( $>0.8 \mathrm{~mm}$ diam.) were obtained by microdissection. Concentrations of oestradiol-17 $\beta$, testosterone and progesterone in blood and follicular homogenates were measured by RIA.

Follicular steroidogenesis was increased significantly on Day 6 after ovulation, at the time when the corpus luteum transforms into an oestrogen-dependent tissue. The ability of developing post-ovulatory follicles to secrete steroids in vitro in response to a gonadotrophic stimulus also increased over this same time interval. Follicular oestradiol production on Days 1 and 2 of pseudopregnancy may synergize with the post-ovulatory secretion of FSH to promote further follicular growth in the pseudopregnant rabbit.
\end{abstract}

\section{Introduction}

The post-ovulatory growth of follicles is of special interest in the rabbit since the developing corpus luteum becomes an oestrogen-dependent tissue by 6 days after ovulation (Hammond \& Robson, 1951 ; Miller \& Keyes, 1978). The luteotrophic oestrogen is supplied by large follicles present in the ovary at the onset of luteal oestrogen dependency; destruction of these large follicles leads to immediate failure of the corpus luteum and termination of pregnancy (Westman, 1934; Keyes \& Nalbandov, 1967; Rennie, 1968). After ovulation in the rabbit a wave of follicular growth occurs, thus repopulating the ovary with large, mature follicles which contain higher amounts of several steroids than do the follicles of smaller size present at Day 2 of pseudopregnancy (Osteen \& Mills, 1980). While the increasing follicular content of steroids would be expected to be reflected in blood concentrations of these hormones, the steroidogenic potential of this developing follicle population of the pseudopregnant rabbit during the transition from luteal oestrogen independence has not been well documented. Since FSH is known to be elevated in the rabbit at 12-36 h after ovulation (Osteen \& Mills, 1980; Mills, Copland \& Osteen, 1981) follicular oestrogen could act synergistically with FSH to stimulate rapid follicular growth and induce LH receptors, as has been shown to occur in the rat (Richards \& Midgley, 1976).

In the present study, ovarian follicular steroids in peripheral and ovarian venous blood were measured at selected days during the early post-ovulatory period when the CL becomes dependent upon follicular oestrogen. The steroidogenic competence of the follicle population after ovulation was also examined both in vivo and in vitro.

* Present address: Department of Obstetrics and Gynecology, Division of Reproductive Endocrinology, Vanderbilt University Medical Center, Nashville, Tennessee 37232, U.S.A. 


\section{Materials and Methods}

Animals

Sexually mature female white rabbits of the New Zealand strain $(3.5-4.5 \mathrm{~kg})$ were obtained from a local supplier and housed in separate cages. Rabbits were maintained at constant temperature in a $14 \mathrm{~h}$ light $: 10 \mathrm{~h}$ dark schedule with pressed food and water ad libitum.

\section{Experimental design}

Pseudopregnancy was induced by injection of 50 i.u. hCG (Ayerst Laboratories, New York, U.S.A.) into a lateral ear vein. Control animals received no injection.

One group of animals was utilized for collection of ovarian vein and peripheral blood on Day 0 (oestrus) while others were used at 24, 48 and $144 \mathrm{~h}$ after hCG injection (Days 1, 2 and 6 of pseudopregnancy). Animals were anaesthetized with ketamine hydrochloride $(40 \mathrm{mg} / \mathrm{kg}$ body wt; Vetalar, Parke Davis, Morris Plains, New Jersey, U.S.A.) followed 5 min later by xylazine hydrochloride ( $8.8 \mathrm{mg} / \mathrm{kg}$ body wt; Rompun, Cutter Laboratories Inc., Shawnee, Kansas, U.S.A.). The ovaries were exposed by a midline incision, the animals were injected with 1000 i.u. sodium heparin and the ovarian vein cannulated with a teflon cannula (i.d. 0.69 mm). Blood was collected from the ovarian vein by gravity flow. Peripheral blood samples were collected simultaneously from the lateral ear vein. Additional ovarian venous blood was collected from some animals that had received a 'challenge dose' of 50 i.u. hCG via the lateral ear vein.

In another study, ovaries were collected on Day 1, 2 or 6 after injection of 50 i.u. hCG. Under $\times 7$ magnification all follicles $\geq 0.8 \mathrm{~mm}$ were dissected out according to a previously published method (Mills, Davies \& Savard, 1971). Follicles containing blood or exhibiting any discoloration were considered likely to be atretic and were discarded. Once the collection process was complete, whole follicles were sectioned into two equal halves and divided into two groups for incubation with LH or for control incubations. This was done to minimize the variability that might exist among individual follicles. Tissues in each group were washed twice with $2 \mathrm{ml} \mathrm{Krebs-Ringer-bicarbonate}$ buffer (KRB) at pH 7.0 (Umbreit, Burris \& Stauffer, 1959) followed by centrifugation at $500 \mathrm{~g}$. Follicular tissues (including the granulosa and theca elements) were incubated in $2 \mathrm{ml} \mathrm{KRB}$ containing $0.02 \%$ glucose $(\mathrm{w} / \mathrm{v})$ with $\mathrm{LH}(5 \mu \mathrm{g}$ ovine $\mathrm{LH}(\mathrm{NIH}-\mathrm{Sl}$ ) $/ \mathrm{ml})$ or with no additions (control incubations). Incubations were carried out at $37^{\circ} \mathrm{C}$ with a gas phase of $95 \% \mathrm{O}_{2}: 5 \% \mathrm{CO}_{2}$, for $3 \mathrm{~h}$, and were terminated by quick freezing.

\section{Steroids}

The following steroids were purchased from New England Nuclear, Boston, Massachusetts, U.S.A.: $\left[2,4,6,7-{ }^{3} \mathrm{H}\right.$ ]oestradiol-17 3 (sp. act. $\left.91 \cdot 3 \mathrm{Ci} / \mathrm{mmol}\right),\left[1,2,6,7-{ }^{3} \mathrm{H}\right]$ testosterone (sp. act. $91 \cdot 1$ $\mathrm{Ci} / \mathrm{mmol}$ ) and $\left[1,2,6,7-{ }^{3} \mathrm{H}\right]$ progesterone (sp. act. $96 \mathrm{Ci} / \mathrm{mmol}$ ). Purity of radioactive steroids was ascertained before use by paper or celite column chromatography. All non-radioactive steroids were purchased from Schwarz-Mann, Spring Valley, New York, U.S.A.

\section{Steroid antibodies}

The antiserum to oestradiol-17 $\beta$ was a gift from Dr D. C. Collins, Emory University, Atlanta, Georgia, U.S.A. This antiserum (TGK) was raised against oestradiol-6-(O-carboxymethyl) oxime thyroglobulin and was utilized at a final assay dilution of 1:70000. The antiserum to testosterone utilized was R-181 (Radioassay Systems Laboratories Inc., Carson, California, U.S.A.). This antiserum was raised against testosterone 19-carboxymethyl ether-BSA and was used at a final assay dilution of $1: 170000$. The antiserum to progesterone $\left(\mathrm{D}_{3}\right)$ was prepared in this laboratory against 4-pregnen-11-hydroxy-3,20-dione hemisuccinate-BSA and used at a final assay dilution of 
1:24 500. This antibody shows less than $1 \%$ cross-reactivity with corticosterone, and several androgens, oestrogens and progestagens (including 20 $\alpha$-dihydroprogesterone: Mills \& Osteen, 1977).

\section{Steroid radioimmunoassays}

The steroid content of blood samples and incubation media was determined by a modification of the radioimmunoassay (RIA) procedure of Abraham (1975) generally used in this laboratory (Mills, 1975; Waterston \& Mills, 1976; Mills \& Osteen, 1977). Due to the high specificity of the available antibodies, it was determined that direct assay of the samples after diethyl ether extraction was sufficient and further chromatographic separation of the steroids on celite columns was not required. The lower limits of sensitivity for the oestradiol- $17 \beta$, testosterone and progesterone assays were 5,10 and $10 \mathrm{pg}$, respectively, with interassay coefficients of variation of $9 \cdot 6,11 \cdot 3$ and $9 \cdot 9 \%$ respectively. Values for water blanks in all the assays were below the sensitivity of the assays.

\section{Gonadotrophins}

The LH preparation used for in-vitro follicle incubation studies (NIH-LH-S16) was supplied by the National Institutes of Health.

\section{Statistical analysis}

Statistical analyses were performed using analysis of variance with Duncan's Multiple range test and Student's $t$ test.

\section{Results}

\section{Ovarian vein and peripheral blood steroid concentrations}

Ovarian vein concentrations of oestradiol were significantly lower on Days 1,2 and 6 of pseudopregnancy than on Day 0 although Day 6 values were significantly higher than those on Days 1 and 2 (Table 1). Peripheral blood levels of oestradiol were much lower than those found in ovarian vein blood and did not change on Days $0,1,2$ or 6 . The testosterone concentrations in ovarian vein and peripheral blood exhibited a similar pattern (Table 1). Values on Day 6 in ovarian vein blood were again lower than those on Day 0 but elevated compared to Days 1 or 2 .

Table 1. Comparison of peripheral blood and ovarian vein blood levels of oestradiol and testosterone collected on Days 0 to 6 of pseudopregnancy

\begin{tabular}{|c|c|c|c|c|c|c|c|c|}
\hline \multirow[b]{2}{*}{ Steroid } & \multicolumn{4}{|c|}{ Peripheral blood } & \multicolumn{4}{|c|}{ Ovarian vein blood } \\
\hline & Day 0 & Day 1 & Day 2 & Day 6 & Day 0 & Day 1 & Day 2 & Day 6 \\
\hline $\begin{array}{l}\text { Oestradiol } \\
\quad(\mathrm{pg} / \mathrm{ml})\end{array}$ & $37 \pm 6$ & $27 \pm 5$ & $30 \pm 5$ & $42 \pm 8$ & $267 \pm 17$ & $131 \pm 15^{*}$ & $119 \pm 23^{*}$ & $215 \pm 15 \dagger$ \\
\hline $\begin{array}{l}\text { Testosterone } \\
(\mathrm{pg} / \mathrm{ml})\end{array}$ & $82 \pm 10$ & $77 \pm 12$ & $79 \pm 16$ & $80 \pm 8$ & $557 \pm 19$ & $314 \pm 49^{*}$ & $252 \pm 18^{*}$ & $462 \pm 23 \dagger$ \\
\hline
\end{tabular}

Values represent mean \pm s.e.m. for duplicate determinations performed on sera from 3 different does.

${ }^{*} P<0.05$ compared to Day 0 value.

$\dagger P<0.05$ compared with values on Days 0,1 and 2 . 


\section{LH-stimulated steroid production in isolated follicles}

As shown in Table 2, LH stimulated production of oestradiol on Days 2 and 6, and of testosterone and progesterone on all 3 days.

Table 2. Effect of $\mathrm{LH}(5 \mu \mathrm{g} / \mathrm{ml})$ on steroid production by rabbit follicles isolated on Days 1, 2 and 6 of pseudopregnancy

\begin{tabular}{lccc}
\hline Steroid & Day 1 & Day 2 & Day 6 \\
\hline Oestradiol & $1.07 \pm 0 \cdot 17^{\mathrm{a}}$ & $3.69 \pm 0 \cdot 47^{\mathrm{b}, *}$ & $5 \cdot 25 \pm 1 \cdot 01^{\mathrm{c}, *}$ \\
Testosterone & $1.98 \pm 0 \cdot 21^{\mathrm{a}, *}$ & $3.99 \pm 0 \cdot 49^{\mathrm{b}, *}$ & $26 \cdot 5 \pm 4 \cdot 3^{\mathrm{c}, *}$ \\
Progesterone & $1.95 \pm 0 \cdot 39^{\mathrm{a}, *}$ & $6 \cdot 0 \pm 1 \cdot 5^{\mathrm{b}, *}$ & $22 \cdot 0 \pm 3 \cdot 8^{\mathrm{c}, *}$ \\
\hline
\end{tabular}

\footnotetext{
Values are stimulation index, mean \pm s.e.m. for 3 incubations and are compared with the equivalent control incubation value which was set at 1.0 .

Within rows, values with different superscript letters are significantly different, $P<0.05$.

* Values significantly different from control values, $P<0.05$.
}

In-vivo hCG-stimulated oestradiol release into the ovarian vein blood

No significant increase in ovarian vein oestradiol concentrations was seen at 15 or 30 min after in-vivo hCG-challenge in rabbits cannulated on Day 1 or Day 2 (Text-fig. 1). However, by Day 6 of pseudopregnancy there was a significant increase in oestradiol release at 15 and 30 min after the hCG challenge $(P<0.05)$, with values at 30 min comparable to those of Day 0 animals.

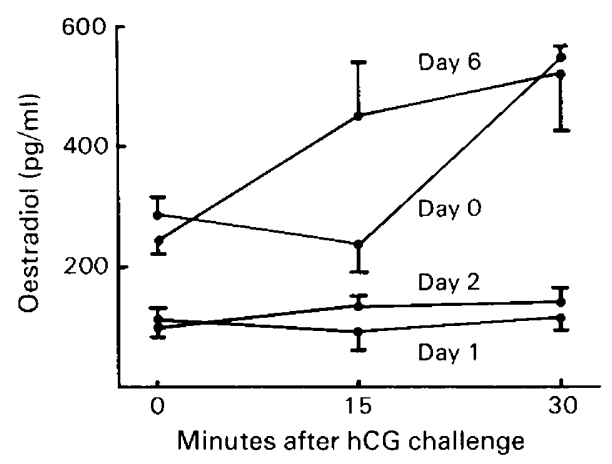

Text-fig. 1. Release of oestradiol into the ovarian vein of rabbits on Days $0,1,2$ and 6 of hCGinduced pseudopregnancy and given a challenge dose of 50 i.u. hCG. Each point represents the mean \pm s.e.m. of duplicate determinations in 3 separate experiments.

\section{Discussion}

In the present study, concentrations of peripheral plasma oestradiol and testosterone were low and did not change significantly despite a rise in ovarian venous blood levels of these steroids. These results are in good agreement with our previous finding of a wave of follicular growth in the rabbit (Osteen \& Mills, 1980) leading to increased output of oestradiol and testosterone into the ovarian venous effluent at Day 6. Hilliard \& Eaton (1971) likewise found such an increase in circulating oestradiol. It is therefore suggested that those newly matured follicles supply the luteotrophic oestrogen for the onset of luteal oestrogen dependence. 
The developing luteal tissue in the post-ovulatory rabbit ovary has been shown to be unresponsive to gonadotrophin stimulation for up to $72 \mathrm{~h}$ after the ovulatory stimulus (HunzickerDunn \& Birnbaumer, 1976; YoungLai, 1977). Many of the large follicles remaining are likely to be atretic since they did not respond to the ovulatory gonadotrophin surge and have low oestrogen content (Osteen \& Mills, 1979). The present study indicated that while LH failed to stimulate oestradiol synthesis above control at $24 \mathrm{~h}$ after injection of $\mathrm{hCG}$, an increase of $2-2 \cdot 5$-fold in both testosterone and progesterone synthesis was seen. D'Amato, Calvo, Stockert \& Bahr (1981) have reported increases in progesterone secretion with repeated gonadotrophin stimulation of perfused isolated rabbit follicles, indicating that progesterone production may be immune to the desensitizing effects of gonadotrophins. However, $\mathrm{LH}$ also stimulates some increase in testosterone secretion as early as $24 \mathrm{~h}$ after hCG-induced pseudopregnancy. By $48 \mathrm{~h}$ an LH induced increase of approximately 4-fold in both oestradiol and testosterone production was demonstrable while progesterone production increased to 6-fold at the same time. At $72 \mathrm{~h}$ the follicles were highly responsive to $\mathrm{LH}$ stimulation in terms of synthesis of all steroids measured. These results indicate that the newly developing follicles may respond to $\mathrm{LH}$ with increased oestradiol synthesis much earlier than $72 \mathrm{~h}$. Whether or not the production of oestradiol by $48 \mathrm{~h}$ of pseudopregnancy represents a return to gonadotrophin sensitivity following the desensitizing effect of the ovulatory stimulus is not known. An alternative explanation is that the small antral follicles at Day 2 of pseudopregnancy may be responsible for this oestradiol production and not the larger follicles remaining in the ovary after ovulation. Small follicles have been shown to possess low levels of LH/hCG receptors (Channing \& Kammerman, 1973) and thus may not have been desensitized by the ovulatory (hCG) stimulus. These maturing follicles may thus develop new $\mathrm{LH} / \mathrm{hCG}$ receptors in response to elevated FSH levels at 24-48 h after ovulation in the rabbit (Osteen \& Mills, 1980; Mills et al., 1981). Early oestradiol synthesis by these developing follicles may be physiologically important since oestradiol acts synergistically with FSH in the induction of follicular receptors for FSH and LH/hCG (Richards \& Midgley, 1976). Additionally, FSH may be important for induction of aromatase activity as suggested by Dorrington, Moon \& Armstrong (1975). The newly developing follicles thus become the population of large steroidogenically competent follicles which is essential in rabbits by Day 6 of pseudopregnancy. It is unclear why these developing follicles did not respond with increased ovarian venous oestradiol levels following the in-vivo hCG challenge at $48 \mathrm{~h}$.

In summary, follicular growth during early pseudopregnancy in the rabbit is marked by an increase in steroid levels measurable in ovarian venous blood. In-vitro responsiveness of these newly matured follicles to gonadotrophin stimulation also significantly increased. These results indicate that follicular steroidogenesis after ovulation increases at the time of or before luteal oestrogen dependency. Follicular steroidogenesis may, however, increase as early as $24-48 \mathrm{~h}$ after the ovulatory stimulus.

We thank Ms Gail Williams and Ms Brenda Gibson for typing the manuscript. The work was supported in part by NIH Grant HD-12290.

\section{References}

Abraham, G.E. (1975) Radioimmunoassay of steroids in biological fluids. J. Steroid Biochem. 6, 261-270.

Channing, C.P. \& Kammerman, S. (1973) Gonadotropin receptors of porcine granulosa cells during follicular maturation. Endocrinology 92, 531-540.

D'Amato, C., Calvo, F.O., Stockert, B. \& Bahr, J.M. (1981) Steroid secretion by perfused rabbit follicles: effect of repeated gonadotropin challenges. Biol. Reprod. 25, 843-850.
Dorrington, J.H., Moon, Y.S. \& Armstrong, D.T. (1975) Estradiol-17 7 biosynthesis in cultured granulosa cells from hypophysectomized immature rats; stimulation by follicle stimulating hormone. Endocrinology 97 , 1328-1331.

Hammond, J. \& Robson, J. (1951) Local maintenance of the rabbit corpus luteum with estrogen. Endocrinology 49, 384-389.

Hilliard, J. \& Eaton, L.W. (1971) Estradiol-17ß, proges- 
terone and 20x-hydroxypregn-4-en-3-one in rabbit ovarian venous plasma. II. From mating through implantation. Endocrinology 89, 522-527.

Hunzicker-Dunn, M. \& Birbaumer, L. (1976) Adenylyl cyclase activities in ovarian tissues. II. Regulation of responsiveness to $\mathrm{LH}, \mathrm{FSH}$, and PGE in the rabbit. Endocrinology 99, 185-197.

Keyes, P.L. \& Nalbandov, A.V. (1967) Maintenance and function of corpora lutea in rabbits depend on estrogen. Endocrinology 80, 938-946.

Miller, J.B. \& Keyes, P.L. (1978) Transition of the rabbit corpus luteum to estrogen dependence during early luteal development. Endocrinology 102, 31-38.

Mills, T.M. (1975) Effect of luteinizing hormone and cyclic adenosine $3^{\prime}, 5^{\prime}$-monophosphate on steroidogenesis in the ovarian follicle of the rabbit. Endocrinology 96, 440-445.

Mills, T.M. \& Osteen, K.G. (1977) 17ß-Estradiol receptor and progesterone and $20 \alpha$-hydroxy-4-pregnen-3-one content of the developing corpus luteum of the rabbit. Endocrinology 101, 1744-1750.

Mills, T.M., Davies, P. \& Savard, K. (1971) Stimulation of estrogen synthesis in rabbit follicles by luteinizing hormone. Endocrinology 88, 857-862.

Mills, T.M., Copland, A. \& Osteen, K.G. (1981) Factors affecting the postovulatory surge of FSH in the rabbit. Biol. Reprod. 25, 530-535.
Osteen, K. \& Mills, T. (1979) Serum LH and FSH levels in the pregnant rabbit. Proc, Soc. exp. Biol. Med. 162, 454-457.

Osteen, K. \& Mills, T. (1980) Changes in the size distribution, and steroid content of rabbit ovarian follicles during early pseudopregnancy. Biol. Reprod. 22, $1040-1046$.

Rennie, P. (1968) Luteal-hypophyseal interrelationship in the rabbit. Endocrinology 83, 323-328.

Richards, J.S. \& Midgley, A.R., Jr (1976) Protein hormone action: a key to understanding ovarian follicular and luteal cell development. Biol. Reprod. 14, 82-94.

Umbreit, W.W., Burns, R.H. \& Stauffer, O.F. (1959) Manometric and Biochemical Techniques. Burgess Publ. Co., Minneapolis.

Waterston, J.W. \& Mills, T.M. (1976) Peripheral blood steroid concentrations in the preovulatory rabbit. $J$. Steroid Biochem. 7, 15-17.

Westman, A. (1934) Untersuchen uber die Abhang ig Keit der Funktion des Corpus Luteum von den Ovarial Follikeln und uber die Bildungs tatte der Hormone in Ovarium. Arch. Gynaek. 158, 476-504.

YoungLai, E.V. (1977) Steroid production by isolated rabbit ovarian follicles: effects of luteinizing hormone from mating to implantation. J. Endocr. 73, 59 65 .

Received 18 October 1983 